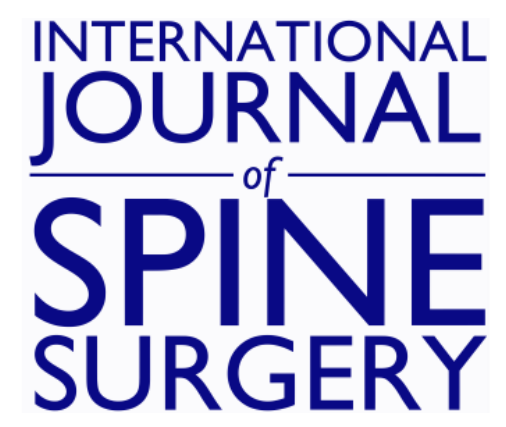

\title{
Anterior Microscopic Transtubular (MITR) Surgical Approach for Cervical Pyogenic C1-2 Abscess: A Case Report
}

Roberto J. Aranibar, Diana Cardenas del Monaco and Phoebe Gonzales

Int J Spine Surg 2015, 9 ()

doi: https://doi.org/10.14444/2056

http://ijssurgery.com/content/9/56

This information is current as of April 26, 2023.

Email Alerts Receive free email-alerts when new articles cite this article. Sign up at:

http://ijssurgery.com/alerts

The International Journal of Shing Surgerih 2397 Waterbury Circle, Suite 1,

Aurora, IL 60504, Phone: +1-630-375-1432

(C) 2015 ISASS. All Rights Reserved. 


\section{Anterior Microscopic Transtubular (MITR) Surgical Approach for Cervical Pyogenic C1-2 Abscess: A Case Report}

Roberto J. Aranibar, MD, ${ }^{1}$ Diana Cardenas del Monaco, PhD, ${ }^{2}$ Phoebe Gonzales, $R N^{1}$

${ }^{1}$ Neurosurgical Associates of San Antonio, San Antonio, TX, ${ }^{2}$ Texas Neurosciences Institute, San Antonio, TX

\section{Abstract}

Osteomyelitis of the spine is a fairly uncommon event following an orthopedic surgical procedure. However, a solitary osteomyelitic abscess of the upper cervical spine is very rare. Surgical intervention is often the only life-saving treatment method. A 70-year-old female patient with diabetes was received from a rural community with symptoms of progressive quadraparesis and progressive respiratory failure. A CT scan of the cervical spine showed a destruction of the $\mathrm{C} 1$ and $\mathrm{C} 2$ complex, as well as the left occipital condyle, and clear evidence of craniocervical instability. She underwent surgical debridement of the abscess via an anterior microscopic transtubular approach, followed by a posterior occipital-cervical fusion. While a transoral approach is a well-established procedure for the anterior clivus/C1-2 area, it is fraught with a high degree of morbidity and mortality. The use of the transtubular anterior cervical approach in this case allowed us to access the C1-2 area with ease and minimal effort. From a technical standpoint, this type of approach for treatment of this condition has not been previously documented in the literature.

KEYWORDS: ABSCESS, OSTEOMYELITIS, ANTERIOR CERVICAL MINIMALLY INVASIVE TUBULAR RETRACTION (MITR), QUADRIPLEGIA, DIABETES VOLUME 9 ARTICLE 56 DOI: 10.14444/2056

\section{Introduction}

Osteomyelitis is defined as an inflammation or infection of bone or bone marrow. Pyogenic vertebral osteomyelitis, disk-space infection of the spine, is a serious complication of diabetes. ${ }^{1-3}$ Patients with diabetes are predisposed to a higher incidence of postoperative joint-related infections. Vertebral osteomyelitis can occur after an infected post-operative joint; the spread is usually hematogenous. Pyogenic vertebral osteomyelitis can cause a rapid rate of diskspace destruction involving single or contiguous vertebral bodies or disc spaces. ${ }^{3}$ Staphylococcus aureus (S. aureus) is the most common pathogen, particularly among those patients who have been previously treated for more resistant forms such as methicillinresistant S. aureus (MRSA). There is no uniform approach to treating a high cervical pyogenic vertebral osteomyelitis nor has a surgical intervention in this area been deemed to be more appropriate than another, although a transoral approach has been utilized for this purpose. ${ }^{4,5}$ Use of the anterior cervical approach using tubular retractors in a cadaver study found a reduction in undue tension or compression of the superior laryngeal nerve or hypoglossal nerves, minimized potential infection risk and tissue trauma, and improve anatomical visualization of the operative field compared to the traditional transoral approach. ${ }^{6,7}$ In this case report, we describe a rare case involving a patient with type 2 diabetes who historically underwent right hip surgery with postoperative development of an abscess due to MRSA. A few weeks later she developed pyogenic vertebral osteomyelitis at C1-2. A combined surgical approach using an anterior microscopic transtubular debridement of the abscesses and a posterior stabilization procedure was performed successfully to treat this serious condition.

\section{Case Report}

A 70-year-old female was admitted to our hospital on 25 November 2013 with progressive quadraparesis and respiratory failure. She had a past medical history positive for uterine cancer, Type 2 diabetes mellitus, hypertension and a more recent history of an abscess following right hip surgery. Patient has undergone drainage of the abscess by the interventional radiologist, followed by six weeks of intravenous (IV) antibiotic therapy to treat MRSA sepsis and hip osteomyelitis. Patient was transferred to our institution with the history of spontaneous neck pain followed 
by progressive weakness of all four extremities and difficulty with her breathing of worsening course within the following month. Finally she was taken by her husband to a local Emergency Department where she was intubated and place on mechanical ventilation. Computed tomography (CT scan) of the cervical spine showed massive destruction of the C1-C2 complex, as well as the left occipital condyle (Figure $1 \mathrm{a}$ and Figure 1b). The question remained whether this was an aggressive neoplastic process, considering her cancer history, or an infection with destruction of these structures. Considering the delicate location of this lesion, there was hesitation about doing a CT guided fine needle aspiration for diagnostic purposes, and since clinically this patient's craniocervical junction was clearly unstable, we decided to proceed with an anterior-posterior combined surgical approach.

\section{Surgical Technique}

The patient was taken to the operating room and placed in the supine position using a horseshoe as a headrest, with cervical light weight traction, being very careful with neck manipulation during positioning. Somatosensory evoked potentials (SSEP) and motor function monitoring was done. A standard anterior cervical approach at the C4-C5 level on the right anterior part of the neck was performed. After retracting the carotid sheath laterally and the esophagus and trachea medially, we identified the anterior surface of the spine; our self-retractor system was positioned under a segment of the longus colli mus-

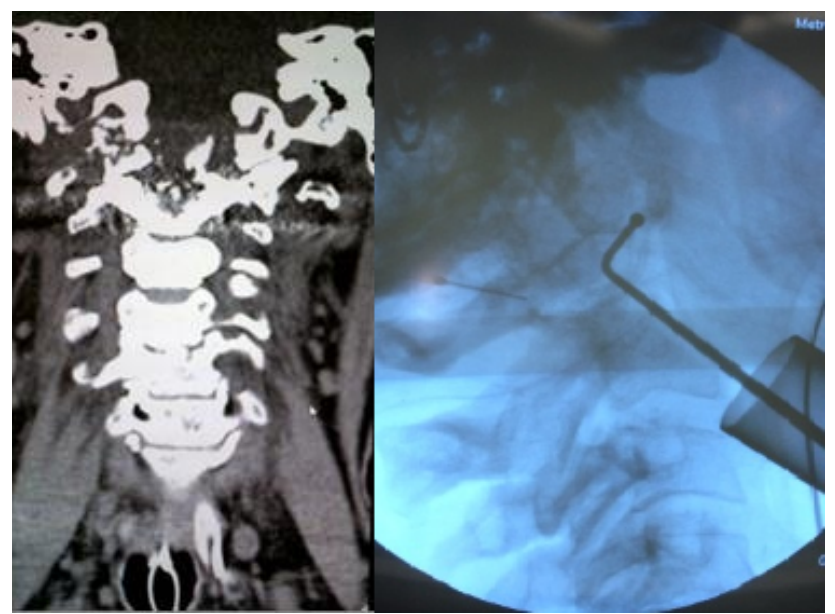

Fig. 1. A) Anterior and Lateral views of CT scan showing destruction of C1-C2 complex and left occipital condyle with possible instability. B) Tubular retractor in place with probe inside $\mathrm{Cl}-2$ abscess. cle fibers, then using gentle finger dissection we were able to reach the $\mathrm{C} 1-2$ area. A $5 \mathrm{~cm}$ in length by $18 \mathrm{~mm}$ in diameter tubular retractor was placed in an angle overlying the C1-2 segment, and fixed in place by the mechanical arm attached to the operating table. The midline position of our tubular retractor was confirmed by anterior posterior fluoroscopy. The operating microscope was brought into the field and under high power magnification we were able to carry out a thorough debridement of the abscess cavity (Figure 2). Tissue sent to pathology failed to show any neoplastic involvement, but heavy granulation tissue consistent with an infectious process. The results of the cultures were positive for MRSA. The abscess cavity was irrigated with antibiotic solution and sprinkled with Vancomycin powder. A Jackson-Pratt drain was left in place and the incision was closed in layers.

Steri-strips were applied to the skin and a Tegaderm dressing. Under manual traction with extreme care, patient was placed in prone position using the threepoint Mayfield headrest. A mid-line incision from the external occipital protuberance to the $\mathrm{C} 6$ level was performed. It was striking the gross instability of the posterior arch of $\mathrm{C} 1$. After exposing enough occiput and lateral masses of the cervical spine down to C5, an occipital plate and screw system was attached to the occiput and connected to a rod-lateral mass screw construct obtaining a solid occipito-cervical stabilization. Adequate bone decortications were done. BMP, augmented with osteostrips, was used as

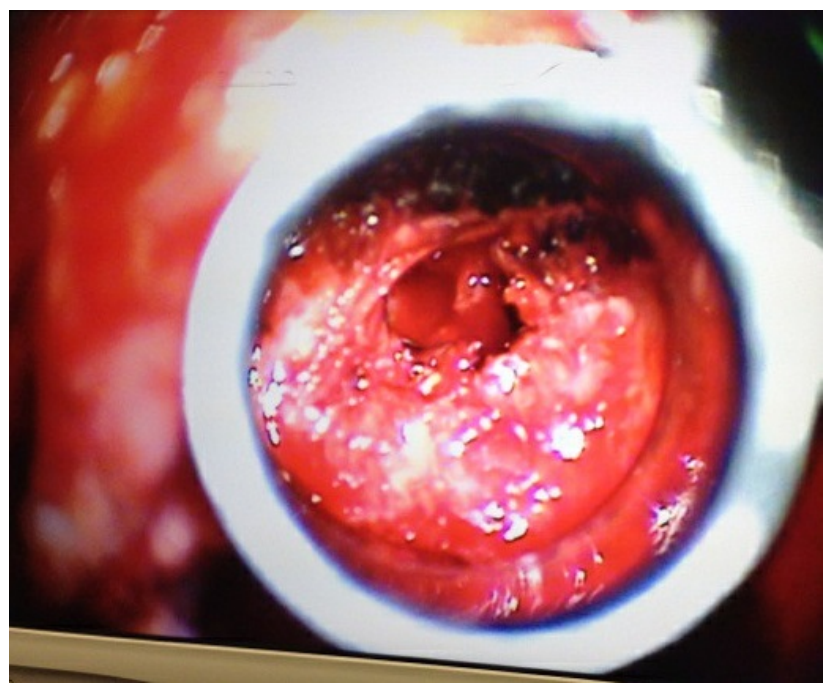

Fig. 2. Microscopic view of the C1-C2 abscess cavity. 
graft material (Figure 3 and Figure 4). The incision was closed in layers after a Jackson-Pratt drain was left in place. Patient was transferred back to the Intensive Care Unit and kept on the respirator.

\section{Pathological Findings and Postoperative Course}

Histopathological examination of the tissue sent and cultures were consistent with Methicillin-resistant Staphylococcus aureus (MRSA). Patient was treated with intravenous Vancomycin for six weeks followed by oral antibiotics. Postoperative complications included ventilator-associated pneumonia with pseudomonas aeruginosa, oropharyngeal dysphagia that required a bedside placement of an enterogastrostomy on a temporary basis. Patient was able to be weaned off the ventilator and was transferred to the rehabilitation ward for an intensive reconditioning program. She was followed very closely by the infectious disease and pulmonary service. During rehabilitation, patient was re-hospitalized for an episode of atrial fibrillation with rapid ventricular response (RVR), with spontaneous resolution. Patient was stabilized and within 72 hours was released back to rehabilitation without restriction. Patient has contin-

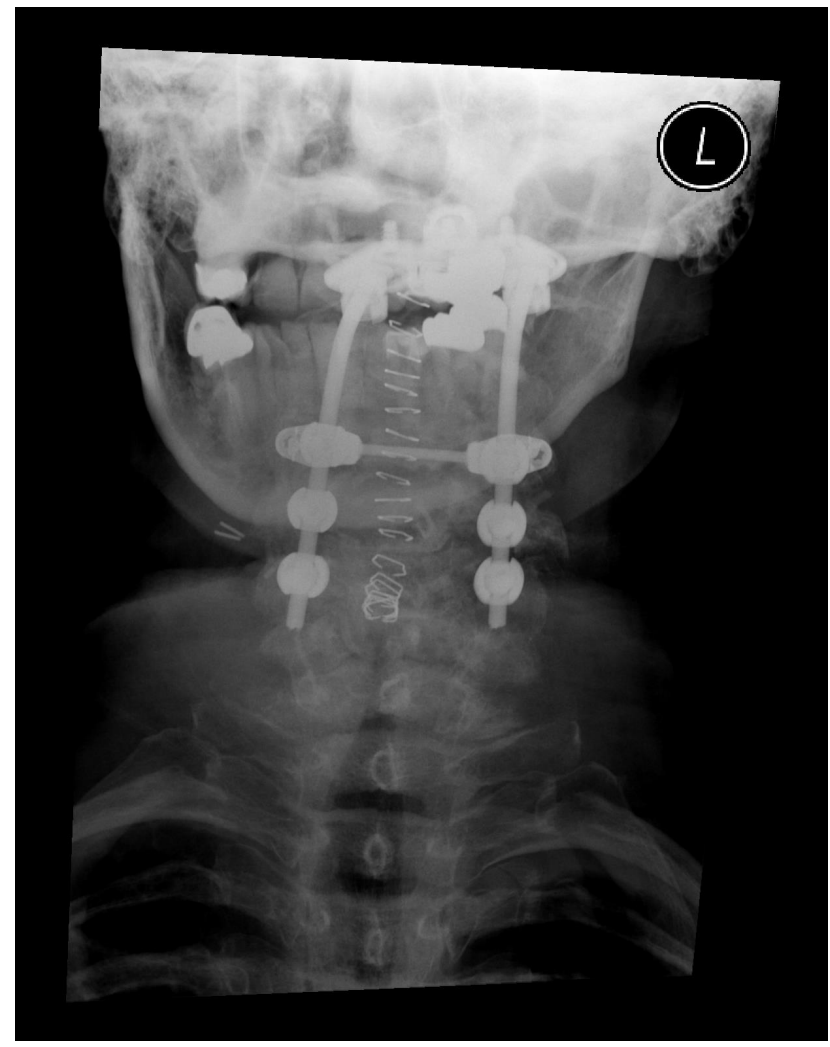

Fig. 3. Anterior-posterior radiograph depicting the occipito-cervical fusion with instrumentation. ued rehabilitation with significant improvements. At 2 month follow up as an outpatient, the patient was able to stand up and take a few steps with some difficulty mainly due to her hip joint sequelae. At 1 year follow up, her motor exam has normalized with continued outpatient physical therapy and she is ambulating with a walker on account of her hip dysfunction. The incision is well healed and a craniocervical CT found complete decompression of the craniocervical junction of the spine with sagittal and axial views showing that the spinal cord is completely free of any kind of mass effect (Figure 5 and Figure 6). Surgical instrumentation remains in good position and she uses a bone growth stimulator to maximize good, solid bony fusion. From an infectious disease standpoint, she has been cleared and is no longer on antibiotics.

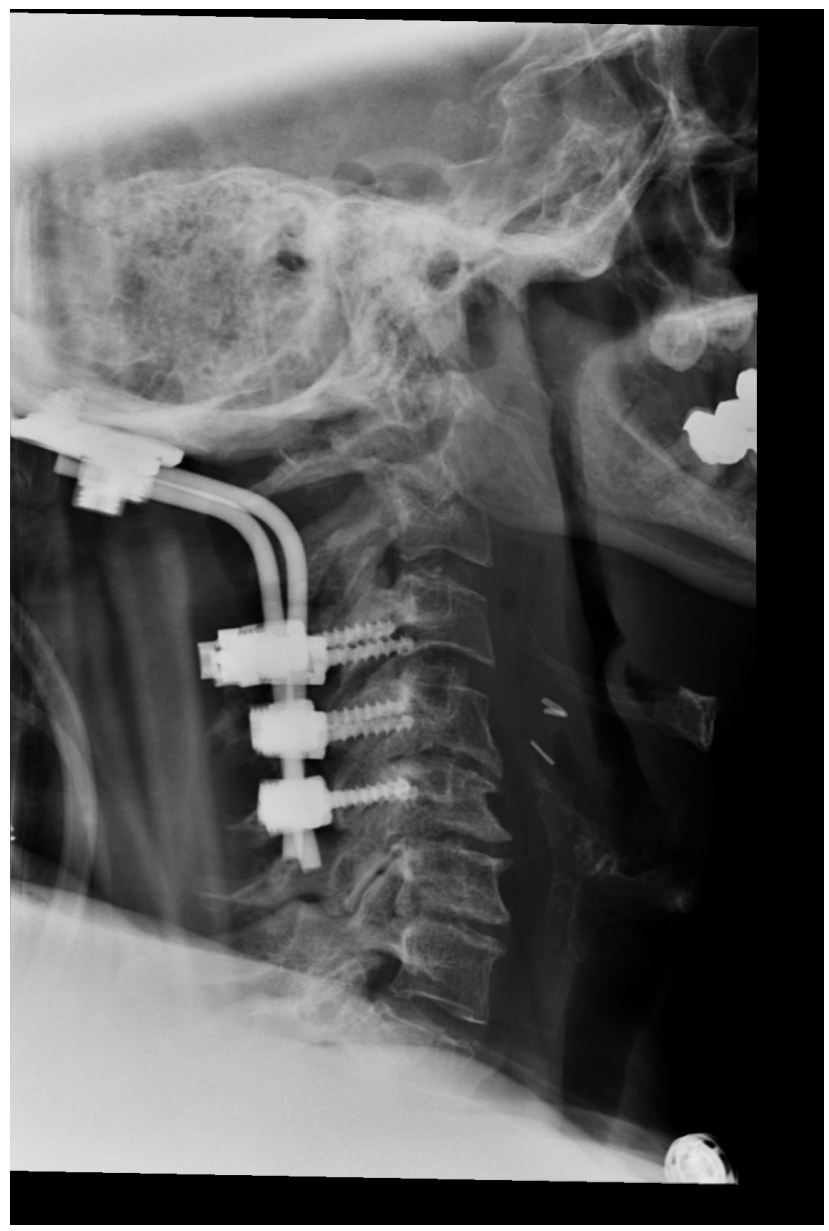

Fig. 4. Lateral radiographic view depicting the occipito-cervical fusion with instrumentation. 


\section{Conclusion}

Successful postoperative recovery documented for this patient indicates that treatment of high cervical pyogenic vertebral osteomyelitis should strongly consider a combined surgical approach of anterior microscopic transtubular debridement of the abscess with a posterior stabilization procedure.

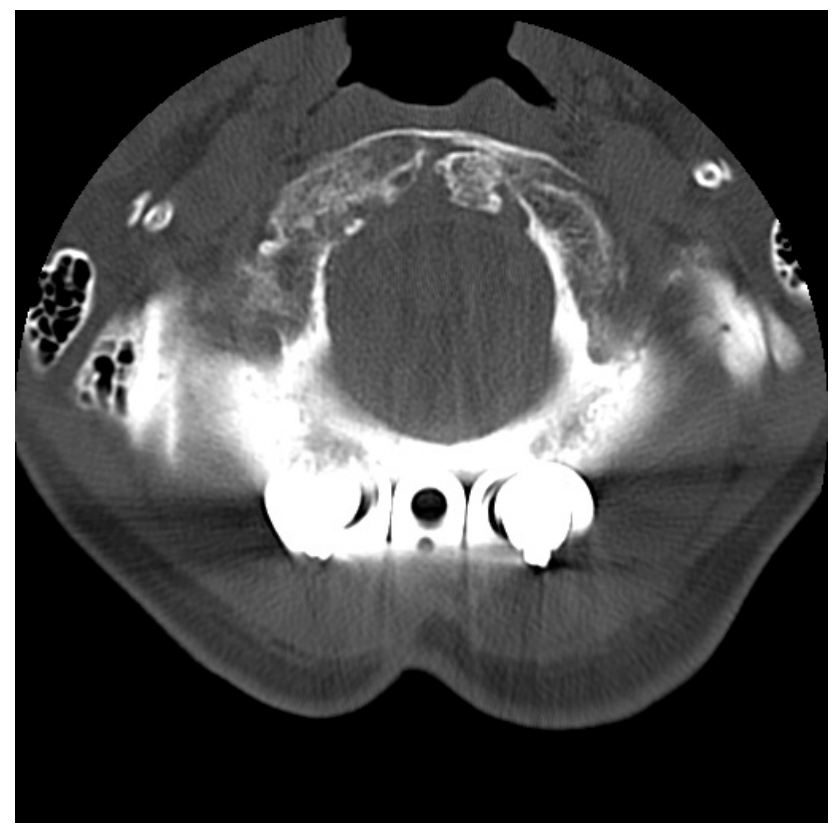

Fig. 5. Sagittal view craniocervical CT with instrumentation (1 year).

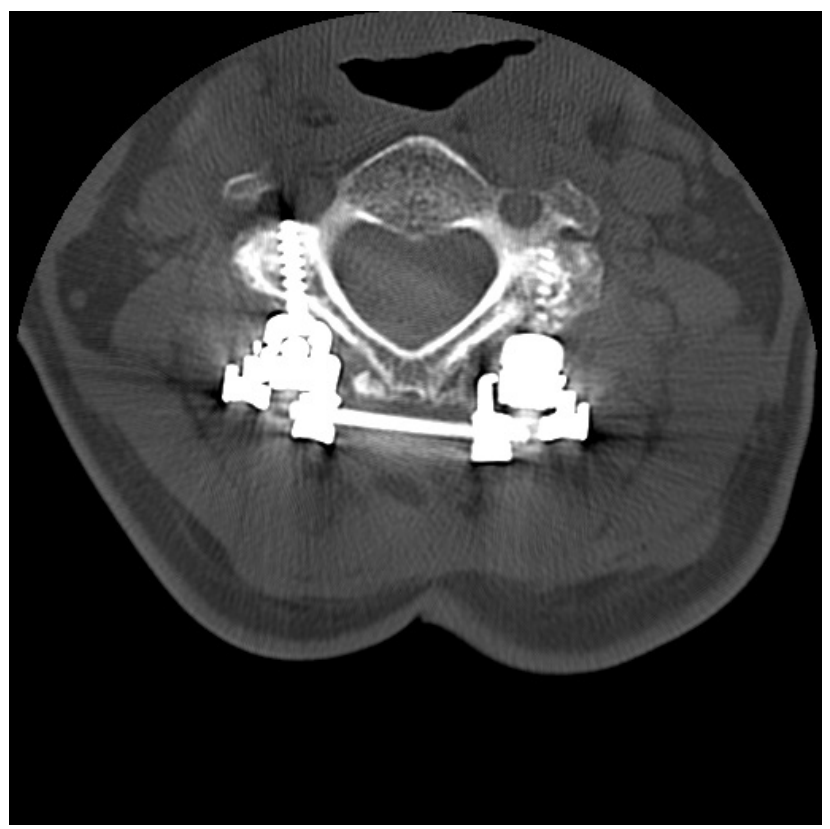

Fig. 6. Axial view craniocervical CT with instrumentation (1 year).

\section{Acknowledgements}

The author(s) wish to acknowledge the following sources: Neurosurgical Associates of San Antonio, P.A., and Metropolitan Methodist Hospital San Antonio, TX

\section{References}

1. DeLure F, Donthineni R, Boriani S. Outcomes of $\mathrm{C} 1$ and $\mathrm{C} 2$ posterior screw fixation for upper cervical spine fusion. Eur Spine J. 2009 [cited 2014 Jun 12].

2. El-Sayed I, Wu J, Ames C, Balamurali G, Mummaneni P. Combined transnasal and transoral endoscopic approaches to the caniovertebral junction. J Craniovertebr Junction Spine. 2010 [cited 2014 Jun $12]$.

3. Isobe Z, Utsugi T, Ohyama Y, Miyazaki A, Ito H, Okuno S, et.al. Recurrent pyogenic vertebral osteomyelitis associated with type 2 diabetes mellitus. J Int Med Res. 2001 [cited 2014 May 4].

4. Jacobson M, Khan S, An H. C1-C2 posterior fixation: indications, technique, and results. Orthop Clin North Am , 2012 [cited 2014 Jun 10].

5. Vender, J., Harrison, S., McDonnell, D: Fusion and instrumentation at $\mathrm{C} 1-3$ via the high anterior cervical approach. J Neurosurg 92.2000 [cited 2014 Jun $12]$.

6. Fong S, DuPlessis SJ. Minimally invasive anterior approach to upper cervical spine: surgical technique. J Spinal Disord Tech . 2005 [cited 2014 Jun 10]. 7. Kim YB, Hyun SJ. Clinical Applications of the Tubular Retractor on Spinal Disorders. J Korean Neurosurg Soc . 2007 [cited 2014 May 4].

\section{Disclosures}

The authors declare no relevant disclosures.

\section{Corresponding Author}

Diana Cardenas del Monaco, $\mathrm{PhD}$, Research Consultant for Neurosurgical Associates, PO Box 291188, San Antonio, TX 78229. dianavcardenas@yahoo.com.

Published 27 October 2015. 
This manuscript is generously published free of charge by ISASS, the International Society for the Advancement of Spine Surgery. Copyright ๑ 2015
ISASS. To see more or order reprints or permissions, see http://ijssurgery.com. 